\title{
PEDAGOGIA DO ESPORTE: PROCEDIMENTOS PEDAGÓgICOS APLICADOS AOS JOGOS ESPORTIVOS COLETIVOS.
}

Larissa Rafaela Galatti

Henrique Barcelos Ferreira

Ylane Pinheiro Gonçalves da Silva

Roberto Rodrigues Paes

\section{Resumo}

O esporte é um fenômeno sócio cultural em destaque no cenário mundial contemporâneo, que se manifesta de múltiplas maneiras, sendo procurado como prática por diversos seguimentos da sociedade, dentre os quais destacamos crianças e adolescentes. Nesse contexto, a partir do referencial da pedagogia do esporte, este estudo preocupa-se em estudar as relações entre o professor de modalidades esportivas coletivas com crianças e adolescentes inseridas no processo de iniciação das referidas modalidades, de forma a propor procedimentos pedagógicos que possam trazer qualidade às aulas, mantendo o foco do processo de ensino, vivência e aprendizagem do esporte não no jogo, mas nas necessidades e interesses de quem jogo, sendo considerados além dos aspectos técnico-táticos, a ênfase nos aspectos sócio-educacionais que a prática esportiva contempla. Assim, o presente estudo observa e descreve um conjunto de procedimentos pedagógicos indicados para processos didáticos em jogos esportivos coletivos que potencializam as possibilidades educacionais, contribuindo para a formação integral de crianças e adolescentes.

\section{Palavras-Chave}

Pedagogia do esporte; Jogos esportivos coletivos; Procedimentos pedagógicos.

\section{THE LESSONS OF PHYSICAL EDUCATION IN AVERAGE EDUCATION: IMPLICATIONS} IN THE QUARRELS ON THEMATIC THE LEARNING AND QUALITY OF LIFE

\author{
Larissa Rafaela Galatti \\ Henrique Barcelos Ferreira \\ Ylane Pinheiro Gonçalves da Silva \\ Roberto Rodrigues Paes
}

\begin{abstract}
The sport is a socio cultural phenomenon in contemporary world, which is manifested in a number of ways, being sought as practice for several follow in society, among which highlighted children and adolescents. In this context, from the benchmark of the sport pedagogy, this study focuses on studying the relationship between the professor of team sports with children and adolescents included in the process of initiation of these procedures in order to propose teaching procedures that might bring quality to sport classes, keeping the focus of the process of education, experience and learning the sport not in the game, but on the needs and interests of the player, and considered beyond the technical and tactical aspects, the emphasis on socioeducational aspects that the practice sports contemplates. Thus, the present study observes and describes a set of procedures educational processes indicated for teaching in team sports games that improve the educational opportunities, contributing to the integral formation of children and adolescents.
\end{abstract}

\section{Key-Words}

Sport Pedagogy; Team sports; Pedagogical procedures.

Conexões: revista da Faculdade de Educação Física da UNICAMP, Campinas, v. 6, ed. especial, p. 397-408, jul. 2008 


\section{INTRODUÇÃO}

A ciência encontra-se em constante evolução, por representar a busca constante pela resolução de problemas surgidos ao longo dos passos da humanidade. Os questionamentos se modificam, as realidades também, proporcionando a necessidade de que a ciência se adeque às mesmas, de maneira a propiciar informações atualizadas e necessárias aos novos contextos que se configuram. Neste panorama, as Ciências do Esporte vem se fortalecendo em função de uma elevada valorização do fenômeno esporte sobretudo na segunda metade do século passado e na contemporaneidade. Neste bloco de ciências, observa-se a Pedagogia do Esporte como uma linha de estudos em ascensão de diversificada abrangência, cujos estudos ligam-se ao organizar, sistematizar, aplicar e avaliar procedimentos pedagógicos adequados para processos de ensino, especialização e treinamento de diversas modalidades esportivas, nos variados contextos onde essa prática se mostra possível.

Considerando o esporte como um fenômeno sócio-cultural com múltiplas manifestações em variados contextos, este estudo busca contribuir para que crianças e adolescentes, quando em contato com o mesmo em um ambiente educacional institucionalizado - formal ou não-formal ${ }^{1}$-, tenham acesso a um programa esportivo que contemple além da prática, estimulando-os a compreender integralmente o esporte, como destaca Paes (2001, p.40).

(...) o esporte, como conteúdo da Educação Física na escola, deverá ser oferecido de forma que o aluno possa compreendê- lo integralmente, conhecendo suas diferentes modalidades; seu ensino deverá abranger conhecimentos teóricos e práticos, dando oportunidade ao aluno de aprender e vivenciar seus fundamentos, compreender suas regras, bem como conhecer sua história e evolução.

Aos apontamentos de Paes, somamos as possibilidades de aprendizagem social por meio do esporte, uma vez que "o convívio humano que se estabelece na prática esportiva pode ser apontado como uma metáfora do convívio humano em outros contextos sociais" (BALBINO, 2001). Atentamos, ainda, que a necessidade de compreensão esporte em sua pluralidade não se restringe ao contexto escolar, devendo estender-se a outros

\footnotetext{
${ }^{1}$ Segundo Demartini e Lang (1985), podemos entender a educação em três níveis:

- Educação formal: que se realiza em agências tecnicamente orientadas para esse fim, as escolas;

- Educação não formal: qualquer atividade educacional organizada e sistemática, fora do sistema formal, visando fornecer tipos selecionados de conhecimentos a grupos particulares da população;

- Educação informal: processo de socialização que se dá ao longo de toda a vida do sujeito e que não é especificamente organizada para propostas de aprendizado.
} 
cenários onde o esporte insere-se, em especial no momento da iniciação esportiva.

\section{OBJETIVO E METODOLOGIA}

O presente artigo sinaliza para uma compreensão da pedagogia do esporte, acompanhada de uma relação de procedimentos pedagógicos que buscam potencializar as possibilidades educacionais do esporte em processos de ensino, vivência e aprendizagem ou especialização de modalidades esportivas, em especial as coletivas. Para tal, foi realizada uma pesquisa bibliográfica, contemplando autores da pedagogia do esporte, assim como aqueles que enfatizam os jogos esportivos coletivos (JECs).

\section{PEDAGOGIA DO ESPORTE E JOGOS ESPORTIVOS COLETIVOS}

A partir dos autores, podemos apontar o esporte como um fenômeno sócio-cultural de grande impacto na contemporaneidade, presente na vida cotidiana das pessoas a partir de diferentes formas de manifestação - seja na prática profissional por atletas especializados, na iniciação esportiva em clubes e praças públicas, em centros de reabilitação, como forma de lazer, entre outros. Seja qual for o contexto em que o esporte se manifesta, Paes (2002) aponta que o fenômeno deve ser tratado a partir de dois referenciais: um ligado às questões técnico-táticas e outro às sócio-educativas. A partir do autor, Galatti (2006, p. 24) elenca características dos dois referenciais, sendo que o referencial técnico-tático diz respeito aos seguintes temas:

- Métodos de ensino e aprendizagem;

- Planejamento ao longo do período (mês, bimestre, semestre, ano...);

- Organização de cada aula/treino;

- Adequação da proposta ao grupo de trabalho;

- Aspectos Técnicos;

- Aspectos Táticos;

- Aspectos Físicos.

O referencial sócio-educativo, por sua vez, relaciona-se aos seguintes objetivos:

- Promover a discussão de princípios, valores e modos de comportamento;

- Propor a troca de papéis (colocar-se no lugar do outro);

- Promover a participação, inclusão, diversificação, a co-educação e a autonomia;

- Construir um ambiente favorável para desenvolvimento de relações intrapessoais e interpessoais (coletivas);

- Estabelecer relações entre o que acontece na aula de esportes com a vida em comunidade. 
Observa-se, assim, a pluralidade de possibilidades educacionais do esporte, seja a fim de difundir suas técnicas e modalidades ou com o intuito de promover e discutir valores, como destaca Paes (2002, p.94):

Para estruturar metodologicamente a pedagogia visando ao ensino dos jogos coletivos é preciso ter o conhecimento (...) promovendo intervenções com graus crescentes de dificuldade. Entretanto, para efetivamente estruturar uma pedagogia do esporte, com o objetivo de contribuir com o processo educacional (...), é preciso avançar em outra direção. Nesse contexto, o referencial socio-educativo constitui-se um ponto sustentador (...) Esse referencial será contemplado na medida em que, além do enfoque técnico-tático, importante na pedagogia do esporte, também se levará em conta princípios indispensáveis para o desenvolvimento da personalidade da criança e do jovem. Destacam-se: cooperação, participação, convivência, emancipação e co-educação.

Nessa perspectiva, estar atento para o contexto sócio-cultural no qual o esporte se manifesta faz-se importante, já que irá determinar quais os valores embutidos na prática esportiva, como esclarece Bento (1999, p. 56) ao tratar da natureza do Esporte:

O desporto é receitado e recomendado para tudo e para nada, como se na sua prática medrasse espontaneamente tudo o que há de mais positivo. Este entendimento é, obviamente, questionável. No desporto, como noutras práticas e como em tudo na vida, há lugar para a ambivalência: tanto se podem realizar valores de sinal positivo como valores de sinal negativo.

$\mathrm{O}$ autor sinaliza para complexidade de valores e modos de comportamentos que se manifestam no esporte, sejam eles considerados negativos ou positivos. Neste artigo, caminharemos para a sugestão de procedimentos pedagógicos que potencializem o trato educacional com o esporte, a fim de contribuir para a vivência e ênfase de valores considerados positivos para o convívio na sociedade em sua totalidade, ou seja, além do ambiente esportivo.

Considerando que o esporte hoje se manifesta por meio de diversas modalidades esportivas, faz-se necessário pontuar que o estudo se incide no momento da iniciação esportiva, sendo destacadas as relações interpessoais desenvolvidas no conjunto dos jogos esportivos coletivos (JECs), uma vez que este tem por essência a convivência em grupos que interagem em busca de um objetivo comum (atingir um alvo) e que este grupo interage com outro com um objetivo semelhante: atingir o alvo da primeira equipe. Dada esta configuração, ressalta-se os três traços fundamentais dos JECs, apontados por Garganta (1995) 
como a cooperação, a inteligência e a comunicação.

Dada a configuração estrutural dos JECs, ressalta-se o potencial dessas modalidades para a vivência de valores e o desenvolvimento de competências importantes para o convívio em sociedade, como a tolerância, inclusão e respeito. Dessa forma, aproximamos o esporte da principal função da Pedagogia, destacada por Bento (1999): o educar:

Educar é levar aquele que está num saber mais baixo para um saber mais alto. E porque estar num saber é estar no nível da realidade que esse saber dá, educar é levar alguém de uma realidade mais baixa para uma realidade mais alta. O que torna patente o carácter instrumental do ensino, da aprendizagem e dos saberes e competências.

Educar é, por conseguinte e obviamente, mudar e modificar. Mudar e adquirir novos modos para ser, para ser mais e melhor, para crescer como pessoa em direção ao mais alto, (BENTO, 1999).

A partir de sua concepção de educar, o autor alerta em relação a dois equívocos relacionados ao educar: (1) somente as crianças são passíveis de processo educacionais (2) a criança deve ser educada (apenas) para ser um bom adulto.

Libâneo (2002) nos aponta que preparar o indivíduo para a vida tornou-se a essência de processos educativos. Entretanto, também alerta que ampliar os conceitos de educação passou a ser um dos fenômenos mais significativos dos processos sociais contemporâneos.

Galatti (2006, p.40), sinaliza que publicações em pedagogia do esporte tem avançado no sentido de ampliar os sujeitos e os objetos de estudo vinculados ao esporte, relacionando alguns estudos que demonstram isso:

(...) como nos estudos de Balbino (2005), que aborda a Pedagogia do Esporte em interface ao esporte profissional; Ferreira, Galatti e Paes, que a ampliam a idéia de iniciação esportiva de crianças para jovens, adultos e pessoas de outra caracterização etária; Trindade (2005) que aborda a Pedagogia do Esporte e a terceira idade; Santana (2005) aborda a complexidade do Esporte, dentre outros.

Entretanto, mesmo em temas recorrentes na pedagogia do esporte, como o esporte infantil e as possibilidades educacionais do esporte - seja na iniciação, seja no treinamento - há necessidade de avanços. Quanto à 
relação esporte e educação, com exemplo, Bento (1999, p. 29) aponta que a Pedagogia do Esporte vai muito além busca por vitórias no campo esportivo, "até porque, a vitória, uma vez consumada, deixa logo de o ser; aponta para tarefas novas e superiores. Além de que o desporte, mais do que celebrar o que em nós abunda, evoca aquilo que em nós falta. Por isso emergem nele o homem alto e o homem baixo, o homem sonhador e o homem vulgar, o homem grande e o homem pequeno".

Temos apontado para a importância de considerarmos as necessidades e desejos de nossos alunos e isto também se aplica às crianças, indivíduos dotados de características próprias, ligadas ao lúdico, à constante necessidade de ligar-se ao imaginário (FREIRE, 1989). Assim, iniciar uma criança no esporte significa adequar o esporte à criança e não a criança ao esporte, elaborando seqüências didáticas e selecionando estratégias e procedimentos pedagógicos tendo como critério as necessidades da infância - como o lúdico, a espontaneidade e a capacidade de adaptar-se a novos conteúdos. Cabe destacar, ainda, a necessidade de que as competições propostas sejam também adequadas à criança, considerando a instabilidade emocional que o ambiente competitivo caracteriza-se e dando ao aluno a oportunidade de vivenciar novas emoções sem constrangimentos.

Nesta perspectiva, o jogo se torna um elemento fundamental, já que nele temos a oportunidade do retorno à origem do esporte, onde as regras podem ser alteradas pelos jogadores, que não têm a obrigação de vencer, embora se mantenha a possibilidade de competir. A competição, segundo Paes (2002), quando tratada de forma adequada, sem valorização exacerbada, pode promover a alegria e o prazer de uma prática que nunca se repete, pois a incerteza presente neste fenômeno, como uma de suas características, pode atuar como um fator de motivação, despertando cada vez mais o interesse pelo esporte.

Como ressaltam Ferreira, Galatti e Paes (2005, p.128)

[...] o professor deve estar atento em promover intervenções positivas; ter a participação, a cooperação, a co-educação, a emancipação e a totalidade como princípios; buscando, assim, valer-se da pedagogia do esporte já discutida e não da simples administração da prática esportivizada.

Assim sendo, sinalizamos os JECs como um conjunto de modalidades esportivas com forte potencial de vivência de princípios e valores, que deve ser potencializado pelo profissional de educação física. Assim, mais do que a prática dos JECs em sua estrutura formal, é necessário competência para propor jogos de diferentes dinâmicas e com variados objetivos. Com este intuito, nos apropriaremos aqui do que Paes (2001) chamou de Jogo Possível, sendo este o jogo que: 
[...] permite adaptações relativas ao espaço físico, ao material, às regras, possibilitando a participação de um grande número de alunos, pois se trata de uma prática de inclusão e não de exclusão; dá oportunidade ao aluno de conhecer e compreender a lógica técnica e a tática do jogo coletivo; busca um equilíbrio entre a cooperação e a competição; amplia os movimentos dos alunos e acentua a ludicidade de sua prática. (...) um facilitador para o resgate da cultura infantil (PAES, 2001, p.36).

O jogo como mediador entre a criança e o esporte, a ser potencializado pelo professor, permite uma flexibilidade de regras que possibilita ao professor tornar adequado à criança praticar o esporte coletivo, tornando possível sua iniciação aos JECs a partir de pressupostos que respeitem a infância, a partir de uma pedagogia e métodos que valorizem a participação da criança, os valores implícitos no jogar e competir, as relações com pais, dirigentes esportivos e árbitros, resgatando nas aulas de esporte os jogos da cultura infantil, preocupando-se, ainda, em criar eventos competitivos com regulamentos alternativos, (SANTANA, 2005).

Vimos, assim, que na pedagogia do esporte o educar é fundamental, sendo necessário, para isso, organizar, sistematizar, aplicar e avaliar procedimentos pedagógicos (PAES, 2002). Em uma aproximação específica da pedagogia do esporte aos JECs, Galatti (2006) aponta que:

(...) à Pedagogia do Esporte, quando no trato com modalidades coletivas, cabe organizar, sistematizar, aplicar e avaliar procedimentos pedagógicos a fim de formar jogadores inteligentes, ou seja, capazes de lidar com os problemas do jogo; e cooperativos, assim como exige um jogo esportivo coletivo, estimulando ainda a transcendência dos conteúdos e atitudes tomadas da quadra para além desta, através de um processo educacional para e pelo o esporte. (GALATTI, 2006, p.36) A partir do exposto, cabe caminharmos para o objetivo central deste estudo: a discussão acerca dos procedimentos pedagógicos a serem explorados no processo de iniciação esportiva dos JECs.

\section{DISCUSSÃO}

Ao longo da história da Educação Física no mundo, a esta foram atribuídas diversas funções. Promover e manter a saúde, capacitar e preparar indivíduos para um determinado fim, desenvolver as capacidades físicas e habilidades motoras em seus praticantes, competir e até mesmo preparar e investigar atletas olímpicos são objetivos da Educação Física. Conseqüentemente, aos profissionais atuantes na área também foram atribuídas diversas funções relacionadas às descrições supracitadas. Entretanto, através de uma compreensão do esporte como um fenômeno complexo, com seus múltiplos significados e possibilidades, evidenciam-se novos papéis a serem desempenhados pelo profissional atuante, dentre os quais destacamos a 
relevância da atuação profissional para contribuir num processo de educação permanente das crianças praticantes de esporte.

Posterior à discussão da pedagogia do esporte e dos apontamentos sobre o momento da iniciação esportiva, faz-se necessário um conjunto de ações coerentes com a proposta. A esse conjunto de ações, que visam não só as questões motoras, mas também às questões sócio-educativas, damos o nome de procedimentos pedagógicos. No decorrer do processo de ensino, vivência e aprendizagem, estes podem, seguramente, contribuir para uma melhoria no ambiente que permeia as aulas de iniciação esportiva.

Diante desses objetivos e das características e exigências dos Jogos Esportivos Coletivos, destacamos alguns procedimentos pedagógicos discutidos por Ferreira (2004), relevantes num processo que busque dar um tratamento pedagógico ao ensino e treinamento das diversas modalidades esportivas coletivas.

O primeiro procedimento pedagógico que discutiremos implica na necessidade do professor propiciar aos alunos momentos de reflexão e diálogo. Com esse procedimento esperamos que situações adversas do ambiente esportivo sejam convertidas em ricas e significativas experiências - não só para o jogo, mas também para suas vidas. Além de contribuir para a autonomia, esse tempo de reflexão propiciado aos alunos, pode ainda auxiliar de forma significativa para uma transformação positiva, tanto em relação à leitura do jogo, como para a criação de inteligentes respostas.

Um outro procedimento que julgamos relevante no processo de iniciação esportiva propõe que o professor tenha a preocupação e se organize a fim de tornar o meio esportivo em um ambiente facilitador de relações interpessoais. Para isso, é necessário que o professor ou técnico propicie ao grupo situações nas quais a cooperação, respeito, solidariedade e companheirismo sejam necessários. A este respeito, Santana (2005) afirma que a criança precisa sentir-se aceita para jogar e para se expressar plenamente; ela precisa se sentir bem para dialogar, questionar, arriscar e propor. Precisa ainda saber que tem o direito de errar e que não será julgada por isso - nem pelo professor e nem pelos outros alunos. Assim, o autor traz o erro como um elemento importante no processo de aprendizagem, apontando que é a partir do erro que a criança descobrirá uma possível solução para o problemas técnico-táticos e de relacionamentos que a pratica esportiva apresentam. Para tal, a melhor estratégia é o jogo, tanto o formal (dentro dos diferentes JECs) como jogos pré-esportivos, dentre outros. Através do jogo e das intervenções do professor ao longo deste, estimula-se o desenvolvimento de processos de leitura do jogo e de observação das ações de seus companheiros e adversários, assim como de cooperar com os mesmos, para uma melhora individual e 
coletiva do jogo. (OLIVEIRA; GRAÇA, 1995).

A partir do momento que o aluno se encontra num ambiente propício a relações de cooperação, respeito, solidariedade e de companheirismo, a criança passa a compreender as suas dificuldades e a dos próprios companheiros de uma outra forma. Passa então a compreender o compartir, o que tende a aumentar as atitudes cooperativas em relação aos problemas não somente do jogo, mas também as dificuldades dos companheiros, enriquecendo desta forma todo o processo de educação para e pelo esporte.

Vimos que iniciar uma criança no esporte significa adequar o esporte à criança e não a criança ao esporte, elaborando estratégias que tenham o lúdico como ponto de partida. Nessa perspectiva, reforçamos $a$ aplicação do jogo como elemento fundamental em todo processo. Porém não basta termos a presença deste elemento nas aulas. É preciso também um procedimento pedagógico em que o professor produza alterações na estrutura do jogo - na intenção de simplificar suas regras, a fim de adequá-lo às crianças e favorecer a aprendizagem, entendendo que durante o processo de ensino, vivência e aprendizagem é fundamental isolar, em alguns momentos, os fatores que diminuem em excesso as chances de sucesso, o que pode desmotivar a permanência do aluno no esporte. Em outros momentos, o oposto precisa ser feito: é necessário propor alterações que tornem o jogo ainda mais complexo, propiciando aos alunos que já dominam um determinado jogo desafios permanentes, estimulando sempre na resolução dos novos problemas que as alterações nas regras dos jogos propiciam. As modificações na estrutura do jogo serão propostas pelo professor para facilitar que os princípios da pedagogia do esporte e algumas das características do jogo sejam preservados, como: a participação efetiva, a acessibilidade, a segurança e a motivação dos praticantes.

Um outro exemplo de procedimento pedagógico relevante num processo de iniciação esportiva propõe a participação permanente em atividades competitivas não formais. Principalmente quando os praticantes são crianças. Nesse caso priorizar a participação em festivais esportivos, em oposição à participação em torneios e campeonatos sem preocupação pedagógica. Os festivais esportivos permitem uma flexibilidade em relação à idade, ao tempo de jogo, a modificação das regras em comum acordo; não há eliminação de nenhuma equipe; todos jogam inúmeras vezes, ou seja, as atividades esportivas não formais, por terem regras livremente concebidas pelos participantes, se tornam mais flexíveis a adaptações que atendam as necessidades, interesses e possibilidades dos participantes. 


\section{CONSIDERAÇÕES FINAIS}

Diante do exposto, nos parece evidente que o jogo pode ser um facilitador pedagógico no processo de ensino, vivência e aprendizagem do esporte, trazendo a seus praticantes inúmeras possibilidades de vivenciar experiências sócio-afetivas individuais e coletivas que podem ser levadas como lições para a vida. No entanto, tais experiências não são necessariamente benéficas, já que existem diversos fatores intervenientes para que isso ocorra.

Para tanto a concepção e o tratamento dados ao esporte devem ser o ponto de partida, embasando as ações praticas do professor. Assim sendo, cabe ao mesmo o abandono da visão simplista de esporte, para então tratá-lo como fenômeno sócio cultural de caráter educativo e a partir de então desenvolver suas aulas priorizando quem joga. Diante disso a utilização dos procedimentos pedagógicos supracitados torna-se valiosa ferramenta para garantir que tais pressupostos sejam otimizados. Desta forma, quando o ensino se dá por meio de procedimentos pedagógicos entende-se que estes melhor se aproximam das características dos Jogos Esportivos Coletivos e, por serem mais flexíveis e criteriosos contribuem para que se respeite à individualidade e os interesses do aluno, além de que exige dos mesmos a criação de respostas aos inúmeros e imprevisíveis problemas impostos pelo jogo e possibilitam o desenvolvimento integral de seus sujeitos.

Garantindo tal ambiente, tornamos possível que os praticantes estejam engajados nas atividades esportivas que escolheram, desfrutando do caráter sócio-educativo do esporte, possibilitando a qualquer indivíduo o aprendizado através do mesmo, seja ele um futuro atleta, admirador ou praticante contínuo da modalidade.

\section{REFERÊNCIAS}

BALBINO, H. F. Jogos desportivos coletivos e os estímulos das inteligências múltiplas: bases para uma proposta em pedagogia do esporte. 2001. 142f. Dissertação (Mestrado) - Faculdade de Educação Física, Universidade Estadual de Campinas, Campinas. 2001.

. Pedagogia do treinamento: método, procedimentos pedagógicos e as múltiplas competências do técnico nos jogos desportivos coletivos. 2005. Tese (Doutorado) - Faculdade de Educação Física, Universidade Estadual de Campinas, Campinas. 2005.

.; GALATTI, L. R.; PAES, R. R. Pedagogia do esporte: considerações pedagógicas e metodológicas no processo de ensino e aprendizagem do basquetebol. In: PAES, R. R.; BALBINO, H. F; Pedagogia do Esporte: contextos e perspectivas. Rio de Janeiro: Guanabara Koogan, 2005.

BALBINO, H, F. Pedagogia do esporte: considerações sobre o processo de iniciação nos jogos desportivos coletivos - um estudo na modalidade basquetebol. 2004. 95 f. ( Monografia) - Faculdade de 
Educação Física, Universidade Estadual de Campinas, Campinas, 2004.

BENTO, J. O. Contextos da pedagogia do desporto: perspectivas e problemáticas. Lisboa: Livros Horizonte, 1999.

FREIRE, J. B. Educação de corpo inteiro: teoria e prática da Educação Física . São Paulo: Scipione, 1989.

GALATTI, L. R. Pedagogia do esporte: o livro didático como um mediador no processo de ensino e aprendizagem de jogos esportivos coletivos. 2006. 139f. Dissertação (Mestrado) - Faculdade de Educação Física. Universidade Estadual de Campinas, Campinas, 2006.

GARGANTA, J. Para uma teoria dos jogos desportivos coletivos. In: GRAÇA, A.; OLIVEIRA, J. (Eds.). O ensino dos jogos desportivos coletivos. 2. ed. Lisboa: Universidade do Porto, 1995. p. 11-25.

LIBÂNEO, J. C. Pedagogia e pedagogos: para quê? São Paulo: Cortez, 2002.

OLIVEIRA, J.; GRAÇA. A. (Ed.). O ensino dos jogos desportivos. Lisboa: Ed. Univ. do Porto, 1995 Faculdade de Ciências do Desporto e da Educação Física, 1995.

PAES, R. R. Educação física escolar: o esporte como conteúdo pedagógico do ensino fundamental. Canoas: Ed. da Ulbra, 2001.

.A pedagogia do esporte e os jogos coletivos. In: ROSE JR. Esporte e atividade física na infância e adolescência. São Paulo: Artmed, 2002. p. 89-98.

SANTANA, W.C. Pedagogia do esporte na infância e complexidade. In: PAES, R. R.; BALBINO, H. F. Pedagogia do esporte: contextos e perspectivas. Rio de Janeiro: Guanabara Koogan, 2005. p. 1-22. 


\title{
Larissa Rafaela Galatti
}

Faculdade de Educação Física - UNICAMP

\author{
Henrique Barcelos Ferreira \\ Faculdade de Educação Física - UNICAMP
}

Ylane Pinheiro Gonçalves da Silva

Faculdade de Educação Física - UNICAMP

\section{Roberto Rodrigues Paes}

Faculdade de Educação Física - UNICAMP

\section{Referência do artigo:}

\section{ABNT}

GALATTI, L. R., et. al. Pedagogia do esporte: procedimentos pedagógicos aplicados aos jogos esportivos coletivos. Conexões, v. 6, p. 397-408, 2008.

\section{APA}

Galatti, L. R., Ferreira, H. B., Silva, Y. P. G., \& Paes R. R. (2008). Pedagogia do esporte: procedimentos pedagógicos aplicados aos jogos esportivos coletivos. Conexões, 6, 397-408.

\section{VANCOUVER}

Galatti LR, Ferreira HB, Silva YPG, Paes RR. Pedagogia do esporte: procedimentos pedagógicos aplicados aos jogos esportivos coletivos. Conexões, 2008; 6: 397-408. 